\title{
Fórmulas diplomáticas en las inscripciones medievales redactadas en romance*
}

\section{Diplomatic formulas in the medieval inscriptions write in Romance language}

\author{
Natalia Rodríguez SuÁRez **
}

\begin{abstract}
RESUMEN ABSTRACT
El presente artículo nos ofrece un estudio de la influencia que las fórmulas documentales romances han tenido en la redacción y formulación de los textos epigráficos, en la Castilla bajo medieval. Esta influencia es especialmente evidente cuando se ponen en relación los testamentos y sus mandas con ciertos tipos de inscripciones. Es el caso de los

This article focuses on the influence that romance documental formulas had in the drafting and formulation of romance epigraphic texts from late medieval Spain. This influence is especially clear if testaments and its mandas with some kind of inscriptions are compared. It is the case of Funera, Monumenta fundationis, Dotationis, etc.
\end{abstract}

Funera, los Monumenta fundationis, Dotationis, etc.

\section{PALABRAS CLAVE}

Epigrafía medieval, inscripciones, diplomática, fórmulas epigráficas, fórmulas diplomáticas, España, Salamanca, Palencia, Ávila, Asturias, Segovia, León.

\section{KEY WORDS}

Medieval Epigraphy, Inscriptions, Diplomatic, epigraphic formulas, diplomatic formulas, Spain, Salamanca, Palencia, Ávila, Asturias, Segovia, León.

Para explicar y comprender el origen de las fórmulas de las inscripciones medievales hay que conocer los factores y el proceso de génesis de estos objetos escritos. Los profesores García Lobo y Martín López distinguen dos fases dentro de ésta; fases que denominan, tomándolas en préstamo de la ciencia del documento

* Fecha de recepción del artículo: 2009-03-25. Fecha de aceptación del artículo: 2009-10-29.

** Depto. de Patrimonio Artístico y Documental. Universidad de León. Campus de Vegazana. 24071 LEÓN. C.e.: nrods@unileon.es 
y aplicándolas en sentido analógico, con dos palabras consagradas ya en la Diplomática: la actio y la conscriptio. La primera hace referencia a la necesidad, por parte de un autor, de difundir un mensaje dirigido a un destinatario más o menos concreto. La conscriptio, por su parte, comprende todo el complejo proceso de materialización del mensaje, que se inicia con la recogida de la petición u orden de realización de la inscripción ${ }^{1}$.

La escuela francesa y la española difieren a la hora de denominar a los protagonistas de estos procesos. La primera, influenciada por la historia del arte, habla de comitente (commanditaire), de autor (auteur) y de artista de la inscripción (artiste).

Retomando las palabras del profesor R. Favreau diremos que:

«...distinguer trois catégories d'intervention. II y a celui qui ordonne et finance l'œuvre, que l'on peut appeler le commanditaire. Le terme d'auteur pourrait être réservé à celui qui fournit le texte de l'inscription. II y a enfin celui qui réalise l'inscription et l'œuvre, l'artiste»².

Por su parte, la escuela española, influenciada por el mundo del documento, — de la Diplomática ${ }^{3}$ - en lugar de comitente (commanditaire), habla de autor, en vez de autor (auteur) alude a rogatario, y sustituye el término de artista (artiste) por el de lapicida, nombre que, por otro lado, utilizaba ya Susuni para la epigrafía romana ${ }^{4}$.

\begin{tabular}{|l|l|l|}
\hline & Escuela francesa & Escuela española \\
\hline Influencia & Historia del arte & Diplomática \\
\hline Quien encarga la inscripción & Commanditaire & Autor \\
\hline Quien redacta el texto de la inscripción & Auteur & Rogatario (ingrossator) \\
\hline Quien realiza la inscripción & Artiste & Rogatario (lapicida) \\
\hline
\end{tabular}

1 Sobre las fases de la génesis epigráfica ver: GARCÍA LOBO, V. Y MARTÍN LÓPEZ, M. ${ }^{a}$ E: De Epigrafía medieval. Introducción y álbum. León, Universidad de León, 1995. GARCíA LOBO, V: «La Epigrafía medieval. Cuestiones de método» en Centenario de la cátedra de «Epigrafía y Numismática» Universidad Complutense de Madrid, 1900-01-2000-01, Madrid, Cátedra de Epigrafía y Numismática, 2001, pp. 77-120.

2 ROBERT, F : « Commanditare, auteur, artiste dans les inscriptions médiévales », Auctor et auctoritas : invention et conformisme dans l'écriture médiévale, actes du colloque de Saint-Quentin_en_Yvelines (14-16 juin 1999), Paris, 2001, pp. 37-59. En ROBERT, F : Épigraphie médiévale. Turnhout, Brepols, 1997, p. 113 también aludía este profesor al mismo tema : «ll y a le plus souvent une pluralité d" « auteurs » dans les inscriptions : celui qui a gravé ou peint le texte, celiu qui l'a commandé et financé, celui qui a fourni le texte et qui peut être lártiste lui-même, le commanditaire, ou encore un lettré de renom ».

${ }^{3}$ Quizá resulten reveladoras e ilustrativas al respecto estas palabras del prof. Vicente García Lobo: «Procedente del campo específico de la Paleografía y de la Diplomática, no llegué a la Epigrafía medieval porque sí. Llegué de la mano de dos maestros a los que desde ahora quisiera rendir homenaje y expresar mi reconocimiento: el ya desaparecido don Tomás Marín y la Dra. D. a María Ruiz Trapero». Cf. GARCÍA LOBO, V: La Epigrafía medieval..., p. 78.

4 SUSINI, G: Il lapicida romano. Introduzione all'epigrafia latina. Roma, Anastásica, 1968, p. 22. 
La redacción del mensaje epigráfico, por tanto, corría a cargo del personaje que la escuela francesa llama auteur, y los especialistas españoles identifican como rogatario; advirtiendo desde ahora que este concepto, lo mismo que en la ciencia diplomática, encierra un conjunto de tareas que podían realizar una o varias personas, especializadas éstas en distintas labores ${ }^{5}$.

Sin embargo, no se puede hablar del rogatario, sea en el ámbito que sea -documentos, libros o inscripciones - sin aludir a la infraestructura imprescindible con que realizar su tarea y que se resume en el concepto de scriptorium, en nuestro caso scriptorium epigráfico ${ }^{6}$. En él se llevaban a cabo todas las tareas conducentes a la materialización de la inscripción.

Allí se tomaba nota de, al menos, los datos esenciales del mensaje que el autor o commanditaire quería difundir. Dicho apunte, por su conexión con el mundo de la Diplomática, se conoce con el nombre de minuta. La minuta se podría definir como el borrador del texto definitivo. Este borrador puede ser extenso, y recoger casi al completo la inscripción posterior. —así lo interpretó Mallon- ${ }^{7}$ pero también, es probable que existiesen minutas breves, en las que únicamente se reflejasen datos concretos, como los nombres de los protagonistas o las fechas. Los profesores García Lobo y Martín López proponen la existencia coetánea de estos dos tipos de minutas ${ }^{8}$.

Las minutas breves eran completadas por el rogatario acudiendo a los formularios $^{9}$. Esta fase se conoce con el nombre de ingrossatio y daría lugar a las minutas extensas, redactadas en escritura oridinaria, que, después, el ordinator transliteraba al soporte epigráfico, para que el lapicida lo convirtiera definitivamente en inscripción.

\section{FÓRMULAS Y FORMULARIOS}

Maximino Gutiérrez dice que estos formularios coartaban y, a la vez, facilitaban la labor del rogatario ${ }^{10}$. Si bien es cierto que, en muchas ocasiones, restringían la libertad creativa del rogatario, que había de redactar el texto completo, ya que se

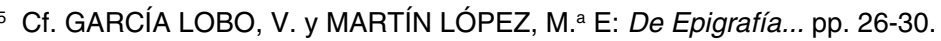

${ }^{6}$ El primero en hablar de «scriptoroia epigraphiques» fue Jean Mallon, rompiendo así la inercia de aplicar este concepto sólo a los talleres librarios. Cf. al respecto GARCIA LOBO, V : La Epigrafía medieval... p. 83.

7 MALLON J : « Scriptoria épigraphiques »Scriptorium, 11, 1957, p. 179 ; MALLON, J : «Pour une nouvelle critique des chiffres dans les inscriptions latines gravées sur pierre "Emerita, 16, 1948, pp.1445 ; MALLON, J : « Une scripcion latine incomplètement gravée » Libyca, 1955, pp. 156-162.

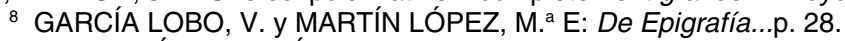

${ }^{9}$ Cf. FERNÁNDEZ FLÓREZ, J.A. y HERRERO DE LA FUENTE, M: «La diplomática y las inscripciones» Actas del II Coloquio Internacional de Epigrafía Medieval, León (en prensa). FAVREAU, R : Les inscriptions medievales, Turhout, Brepols, 1979, pp. 34-40.

10 GUTIÉRREZ ÁlVAREZ, M: Provincia de Zamora. Estudios: Corpus Inscriptionum Hispaniae Mediaevalium, dir. Por V. García Lobo, (Monumenta Palaeographica Medii Aevi, Series hispanica), I/2, Turnhout-León, Brepols, 1999, p. 203. 
convertían en modelos copiados constantemente, no lo es menos que, en no pocas ocasiones, el redactor sabía romper moldes y dar rienda suelta a sus conocimientos literarios, y lingüísticos también, y conferir al texto un sabor personal. De hecho, contamos con no pocos ejemplos en que el tenor textual se aleja notablemente de las fórmulas habituales.

Hemos de advertir que no se conserva ningún formulario medieval o, al menos, no los conocemos; pero su existencia y circulación son innegables, toda vez que la repetición de fórmulas en inscripciones de tiempos y lugares distintos lo acreditan ${ }^{11}$.

Estos modelos o formularios estaban redactados a partir de textos bíblicos y litúrgicos fundamentalmente; aunque no se descuidaron los textos clásicos, las crónicas e, incluso, los documentos. Atendiendo a la fuente de esas fórmulas, las inscripciones se vienen clasificando en librarias y diplomáticas ${ }^{12}$.

Las fórmulas librarias - como nos indica su nombre- han sido tomadas del mundo de los libros, sean: litúrgicos, de la Biblia, de obras clásicas, de obras literarias, etc. Por su parte, las fórmulas diplomáticas se inspiran en los textos documentales, cuyo mensaje se quiere perpetuar en la inscripción. Son precisamente estas fórmulas las que nos proponemos estudiar aquí, aunque no todas; solamente las de los documentos redactados en lengua romance.

Quizá debamos dejar bien sentado, desde el principio, que nuestras inscripciones diplomáticas, aunque guardan una estrecha relación con el documento -ambos son objetos escritos, a veces, redactados en un mismo scriptorium ${ }^{13}$ — difieren radicalmente de él en su funcionalidad. La inscripción medieval jamás tendrá el valor jurídico del documento ${ }^{14}$, mientras que la función primordial de la inscripción es la publicidad ${ }^{15}$.

Habida cuenta de todo esto -identidad de scriptorium, mensajes documentales, calígrafos comunes, etc.- se comprende fácilmente que los textos documentales y sus fórmulas hayan podido influir, y de hecho hayan influido, en los textos epigráficos. Y no sólo eso: las influencias alcanzan también a los aspectos gráficos.

11 Sobre el tema puede consultarse para el mundo romano CAGNAT, R: «Sur les manuels professionels des graveurs dínscriptions romaines» Revue de Philologie et de litterature ancienne $\mathrm{n} .{ }^{\circ} 13$, Paris 1889, pp. 51-65 y para la Epigrafía medieval FAVREAU, R: Épigraphie..., pp. 141-164.

12 Cf. GARCIA LOBO, V. Y MARTÍN LÓPEZ, M. ${ }^{a}$ E: De Epigrafía..., p. 35.

13 GARCÍA LOBO, V: «La Epigrafía medieval...».

14 PAOLI, C: Diplomática, Florencia, Nuova ed. aggiornata, 1942, p. 18 define el documento como «Testimonio escrito de un hecho de naturaleza jurídica redactado con arreglo a formas determinadas que tiene como finalidad darle fe y fuerza probatoria». No obstante, quizá podríamos apurar aún más las afinidades entre las inscripciones diplomáticas y los documentos, considerando aquellas, tal y como lo hizo en su día el prof. Ángel Canellas, como documentos narrativo y, dentro de ellos, como «Actas de notoriedad». Cf. CANELLAS, A: Diplomática Hispano-Visigoda, Zaragoza, Instituto Fernando el católico, 1979, pp. 76-77.

15 GARCÍA LOBO, V: Los medios de comunicación social en la Edad Media. La comunicación publicitaria. Lección inaugural curso académico 1991-92, León, Universidad de León, 1991, p. 37; MARTíN LÓPEZ, M. ${ }^{a}$ E: «Centros escriptorios epigráficos de la provincia de Palencia» en De Litteris, manuscriptis, inscriptionibus...Festschrift zum 65. Geburtstag von Walter Koch, Wien, Böhlau, 2007, p. 203 
Así, el nexo de la s y la t minúsculas de la palabra magíster en la Intitulatio necrologica, de la catedral vieja de Salamanca, nos habla de un calígrafo habituado a la ejecución de documentos carolinos ${ }^{16}$. (Fig. 1).

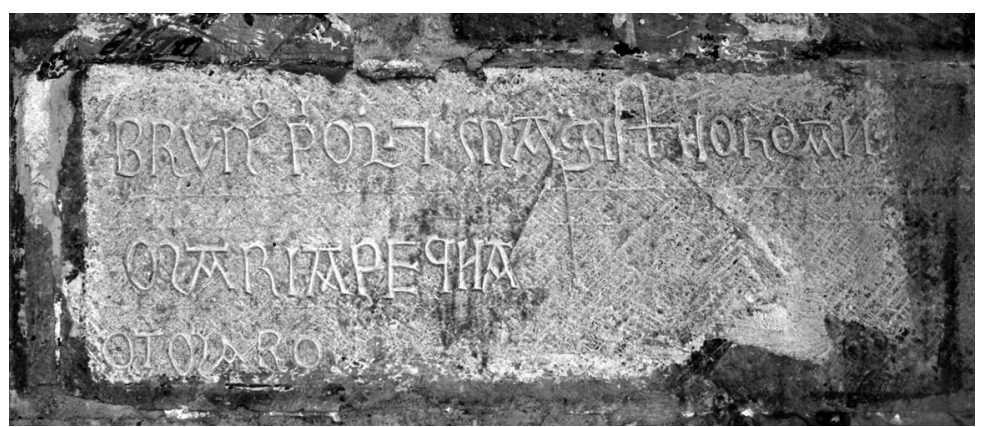

Fig. 1. Intitulatio necrologica (Colección fotográfica Corpus Inscriptionum Hispaniae Mediaevalium).

Esa misma influencia podemos comprobarla en el Epitaphium sepulcrale de Gonzalo, en el museo de los caminos de Astorga ${ }^{17}$ (Fig. 2).

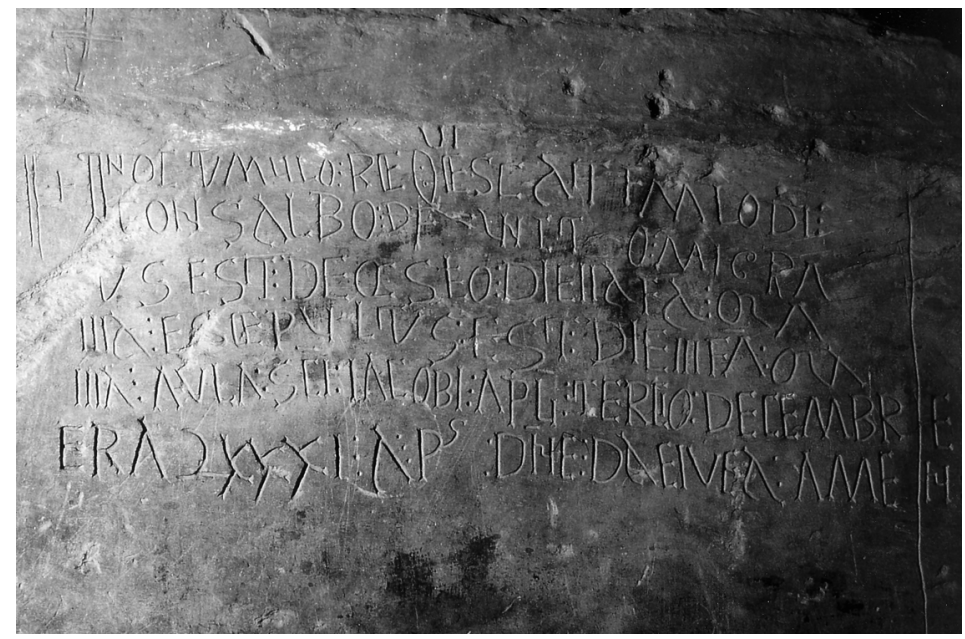

Fig. 2. Epitaphium sepulcrale. (Colección fotográfica Corpus Inscriptionum Hispaniae Mediaevalium).

16 Recordamos que la escuela madrileña del ya desaparecido Tomás Marín, sostiene que la escritura carolina en Castilla y León perduró hasta su definitiva transformación en gótica en la primera mitad del siglo XIII.

17 MAÑANES PÉREZ, T: Inscripciones latinas de Astorga, Valladolid, Universidad de Valladolid, 2000, p. 149. 
Otro caso, especialmente llamativo en este sentido, nos lo ofrece una Suscriptio de las pinturas de la iglesia de Piedrahita de Ávila. En ella se aprecia como el rogatario utiliza una tipología de letra propia de los documentos: la letra procesal (Fig. 3).

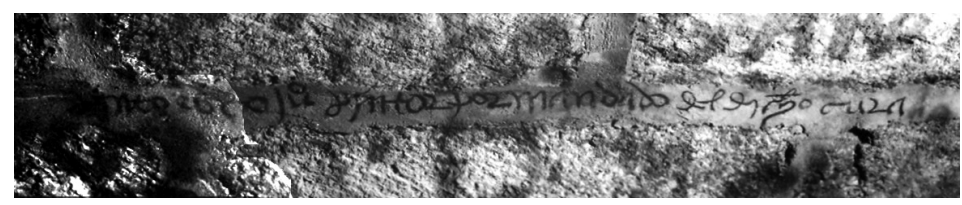

Fig. 3. Suscriptio (Colección fotográfica Corpus Inscriptionum Hispaniae Mediaevalium).

Volviendo a nuestro cometido, las fórmulas diplomáticas de las inscripciones romances, debemos señalar que las influencias documentales son más acusadas aún en las inscripciones latinas, que no nos corresponde estudiar ahora. Señalemos, no obstante, que, en estos epígrafes latinos, es relativamente frecuente encontrar sactiones que intentan coartar el incumplimiento de lo establecido en el texto. Cláusulas que se nos muestran como reinterpretaciones de otras análogas en los documentos. Tal sería la sanctio con que el abad Sabarico de San Miguel de Escalada hizo narrar su epitafio de 1059:

Non abea parte cum Christo omo qui de isto loco sakare. Amen ${ }^{18}$

También nos recuerda al mundo del documento, aunque desprovisto de todo valor jurídico, el signum tabellionis como distintivo del rogatario de alguna inscripción. Citemos como ejemplo la Roboratio del abad Pelagius de Perazancas de Ojeda (Palencia), del año $1076^{19}$ (Fig. 4).

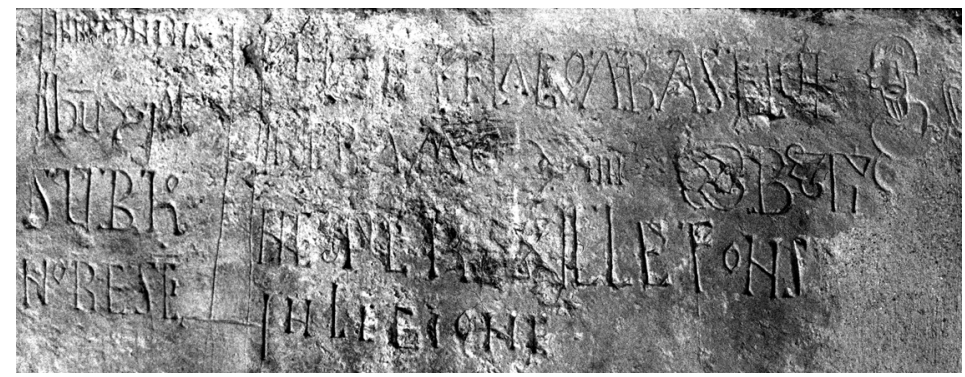

Fig. 4. Roboratio (Colección fotográfica Corpus Inscriptionum Hispaniae Mediaevalium).

18 GARCÍA LOBO, V: Las inscripciones de San Miguel de Escalada. Estudio crítico. Barcelona, El albir, 1982, pp. 69-70.

19 Agradecemos a la profesora Martín López, que nos facilitase esta inscripción, que forma parte del corpus epigráfico, que sobre la provincia de Palencia viene realizando. 
En fin, y para no extendernos más, Invocationes, Intitulationes y Datationes de muchas inscripciones nos recuerdan el formulario típico documental, como ya había señalado en su día el profesor Angel Canellas: «...inscripciones originales, útiles para el conocimiento del formulario documental hispano-visigodo en punto a protocolos y datas» ${ }^{20}$.

\section{LAS FÓRMULAS DIPLOMÁTICAS ROMANCES}

Las inscripciones en lengua vulgar comienzan a aparecer en la segunda mitad del siglo XIII, y se hacen habituales en el siglo XIV. Hemos de reconocer, lo que ya advertimos al comienzo, que las fórmulas diplomáticas, tomadas directamente de los documentos, en las inscripciones en romance no son tan abundantes como las latinas. De hecho, se reducen prácticamente a los epígrafes que reproducen mandas testamentarias, mientras que el resto son mucho menos representativas.

\section{Fórmulas testamentarias}

A partir de mediados del siglo XIII comienza a sentirse la necesidad de perpetuar, en inscripciones, algunas mandas testamentarias de clérigos y laicos que legan a una determinada iglesia ciertos bienes, a condición de que se celebren por su alma sufragios anuales. De esta manera, se garantizaba su cumplimiento, a pesar del paso del tiempo, sin descartar cierta intención propagandística y publicitaria para el testador y su linaje ${ }^{21}$. Son varios los especialistas en el tema que han puesto de relieve que las mandas testamentarias son las fórmulas diplomáticas más comunes en este periodo ${ }^{22}$. El estudio de los epígrafes españoles así lo demuestra, copiando, unas veces, fielmente el texto del testamento, y, en otras ocasiones, reinterpretándolo.

La profesora Martín López también aludió a ello en uno de sus artículos, donde mostraba la similitud entre el testamento y el Epitaphium de Adán Pérez, canónigo de la iglesia de León ${ }^{23}$. Dice así la manda testamentaria:

«A los bachilleres (mando) la metad de las casas que yo he enna PinganieIla...Et elas vinnas de Falualles, Por que canten cada anno enna eglesia de Regla

20 CANELLAS, A: Diplomática, p. 15.

${ }^{21}$ MARTÍN LÓPEZ, M. ${ }^{\text {a }}$ : «El documento como fuente para la epigrafía» en La documentación para la investigación: Homenaje a José Antonio Martín Fuertes, León, Universidad de León, 2002, p. 369.

22 FAVREAU, R : Épigraphie..., p. 170. « A partir du XIIle siècle, on trouve en grand nombre des inscriptions de fondations d'anniversaires, fêstes, aumônes, qui reprennent exactement les clauses des charter ou des testaments ». SANTIAGO FERNÁNDEZ, J. de: «La epigrafía bajomedieval en Castilla » II Jornadas científicas sobre documentación de la Corona de Castilla (siglos XIII-XV), Madrid, Universidad complutense, 2003, p. 253.

${ }^{23}$ MARTÍN LÓPEZ, M. ${ }^{a}$ E: «El documento ...»,p. 370. 
al altar de Santa Catherina, las visperas sua vigilia e en so dia que canten una misa por mia alma e salgan sobre mi sepultura» 24

Por su parte, la cláusula epigráfica la resume:

«... lexo a los bachilleres vnas casas en León, a la Pinganiella et viñas et heredamientos en Falvales, et por esto han de cantar cada anno en vesperas de Santa Cathalina las viesperas et otro dia la misa et fazer sa[lir] sobre sua sepultura... ${ }^{25}$

Comprobamos que en la inscripción se reproduce casi literalmente la manda del testamento. Esto debió ser muy frecuente, aunque hoy no podamos comprobarlo en todas los ejemplos de este tipo, por la pérdida del testamento original.

Pero en los testamentos encontramos dos tipos de mandas: las terrenales y las piadosas. Las primeras son las que aluden a cuestiones de herencias, pagos de deudas y disposiciones familiares, mientras que las segundas son las que pretenden servir de «medio de auxilio a su «pasamiento» de este mundo al otro» ${ }^{26}$ Serán estas últimas las únicas que servirán de formulario a los epígrafes. El análisis de ellos nos permite hacer algunas distinciones dentro de este segundo grupo.

En primer lugar, podemos encontrar alusiones a ofrendas funerarias, comunes en todo tipo de testamentos. Consisten, éstas, en la donación a la iglesia de distintos ofrecimientos. En especial se mencionan el pan, el vino y la cera o las luminarias. Traemos aquí uno de los muchos ejemplos que podemos encontrar entre los testamentos castellanos, el de Teresa García, que forma parte de la colección documental del monasterio de Santa María de Carbajal. Una de sus mandas dice así:

«Mando me oferendar ses selmanas de pan e de vino e de çera, segunnd costumbre de la dicha ciuda, lo que mis testamentarios touieren por bien ${ }^{27}$

En ocasiones este tipo de mandas pasa a las inscripciones. Éste es el caso del Epitaphium sepulcrale del caballero Lope de Cernadilla, en el Museo provincial de Segovia, datado en 1433. El texto dice así:

«...el qual dexo a esta iglesia quinse fanegas de pan de encense...»²8

${ }^{24}$ Cf. MARTÍN FUERTES, J. A: «Colección documental del archivo de la catedral de León (13011350) XI» Fuentes y estudios de historia leonesas, 59, León, Centro de Estudios e Investigación «San Isidoro", 1995, n. ${ }^{\circ} 2918$.

25 Apéndice, n. 3.

26 RODRIGO ESTEVAN, M. ${ }^{a}$ L: Testamentos medievales aragoneses. Ritos y actitudes ante la muerte (siglo XV), Zaragoza, Ediciones 94, 2002, p. 125.

27 DOMíNGUEZ SÁNCHEZ, S: “Colección Documental del monasterio de Santa María de Carbajal (1093-1461) » Fuentes y Estudios de Historia Leonesas, 87, León, Centro de Estudios e Investigación «San Isidoro», 2000, pp. 371-373.

28 MARTÍNEZ ÁNGEL, L: Inscripciones medievales de la provincia de Segovia, León, Universidad de León, 1999, pp. 127-128. Apéndice, n. 19. 
La alusión a las quince fanegas dejadas a la iglesia, en la que debió enterrarse el difunto, alude, claramente, a una de las mandas testamentarias, que sin duda se recogía en su testamento. Y aunque este testamento ha desaparecido, es fácil compararlo con el expuesto anteriormente.

Otro caso, en el que se copian estas ofrendas funerarias, nos lo ofrece el Epitaphium sepulcrale de Sebastián Ruano Mozo, en la iglesia de San Juan de Zamora, fechado en 1474 y hoy desaparecido. Dice así:

«... Dejo a la cofradia de Nuestra Señora una misa, a la fabrica doce cargas de pan en cada anno, con cargo que se han de decir una misa rezada... ${ }^{29}$

Los ejemplos muestran claramente como estos encargos, tan habituales en los testamentos, en ocasiones, se decidía que fueran copiados en algunas inscripciones. Pero, ¿cuál sería la función que desempeñaba la copia de este tipo de mandas? ¿Y por qué se decide ponerlos en una inscripción? Si analizamos detenidamente el testamento antes expuesto, observamos que el difunto pone esta ofrenda en manos de un testamentario. Parece claro, pues, que la razón por la que se habría de dar publicidad a este hecho, hay que buscarla en la necesidad de evitar que los mandatarios, a los que alude el documento, la incumplieran.

Un segundo tipo de mandas testamentarias son las que aluden al encargo de determinado número de misas por el alma del difunto. Éstas también eran habituales en cualquier tipo de testamento, y únicamente variaban en la cantidad de las mismas, en función del poder adquisitivo del personaje que teste. Como es lógico, este encargo se asociaba a la dotación de determinados bienes para sufragar los gastos de esas misas. Al igual que en el caso anterior, las mandas de misas se convirtieron en fórmulas habituales. La inscripción, antes mencionada, de Sebastián Ruano Mozo, ya recogía este tipo de encargos, pero podemos citar otros muchos ejemplos, como la Donatio de ciertos bienes por parte de Mendo y su mujer Oro Gil, en la iglesia de San Justo de Segovia que dice:

«...dieron seis arençadas de c[...]maras et quatro que son en la Lastriella sobre Cigondela por capellania a los prestes de sancti luste que son et seran, et nos los prestes don Macarbo et Diego Peres et don Martin et don Pedro lones obligamos a nos et a los otros prestes que vernan despues de nos que cantemos cada dia una missa de requiem ${ }^{30}$

El Epitaphium sepulcrale de Santa María de Horta en Zamora, presenta otro ejemplo:

«...dexo a esta iglesia quatro pares de casas porque diga una misa cantada cada biernes con su responso sobre esta sepultura... ${ }^{31}$

29 GUTIERREZ ÁlVAREZ, M: Corpus..., p. 85. Apéndice, n. 17.

30 MARTÍNEZ ÁNGEL, L: Inscripciones ..., pp. 104-105. Apéndice, n, 9.

31 GUTIÉRREZ ÁLVAREZ, M: Corpus..., pp. 80-81. Apéndice, n. 13. 
En el Mandatum de la iglesia de San Vicente en Ávila, también se alude al mismo tema:

"Cura y clerigos desta iglesia an de dezir cada semana perpetuamente en esta capilla, en el altar de san Antonio, lunes, misa de Requiem, ... por las almas de Gomez Macav y su muger y difuntos. Dotaron para esto tres yugadas de eredad en Rio Cavado.» ${ }^{32}$.

De nuevo nos preguntamos por qué se plasman en una inscripción este tipo de mandas. La lectura de los letreros nos indica que, en esta ocasión, es la iglesia la encargada de cumplir con estas obligaciones, y la inscripción iría dirigida a que esta entidad cumpliese con los encargos por los que se le había pagado.

Junto a las misas, también los aniversarios se convierten en fórmulas epigráficas. Consistían éstos en una celebración eucarística conmemorando el día de la muerte del difunto, aunque en ocasiones ésta fecha se puede trasladar a la festividad de la devoción personal del fallecido. Es frecuente, por tanto, encontrar en los testamentos alusiones a ellos, como este testamento de Miguel Falcón, mercader de Daroca:

«quel dia que mi cuerpo sera sepelido, en aquell dia se celebre hun aniversario por los prior e canonges de la dita iglesia en cadahun anyo pepetuament»33

En otros casos el número de aniversarios se ve aumentado. El testamento de Antonia de Aínsa nos sirve de ejemplo:

«que los ditos canonges hayan de celebrar e celebren perpetuament cada un anyo quatro aniversarios, el uno la vispera de Sant Miguel de Setiembre, el otro la vigilia de Nadal, el otro la vispera de Santa María candelero e el otro el primero dia de Cuaresma» ${ }^{34}$.

Estas mandas son copiadas en determinadas inscripciones. Sirva de ejemplo el Epitaphium sepulcrale de Lope Ramírez y su segunda esposa, Isabel González de Coca, que estaba en la iglesia de San Pedro en Arévalo, provincia de Ávila.

«...y entre otras buenas obras que dexo, doze aniversarios en cada mes, uno que dizen los sennores del cabildo en esta capilla ${ }^{35}$.

Lo mismo podemos ver en el Epitaphium sepulcrale de Isabel, en la iglesia de San Esteban de Segovia, en el muro oeste del pórtico. Dice así:

«...deue u[...fa]zer cada anno [un aniversario] de missas [...][..s] ermana de $[\ldots]{ }^{36}$

32 Apéndice, n. 21.

33 Publicado por RODRIGO ESTEVAN, M. ${ }^{a}$ L: Testamentos... p. 131.

34 Ibidem.

35 Apéndice, n. 16.

36 MARTÍNEZ ÁNGEL, L: Inscripciones... pp. 84-85. Apéndice, n. 1. 
Si comparamos los dos ejemplos documentales con las inscripciones, nos damos cuenta de que efectivamente esta manda testamentaria se convirtió en formulario.

La finalidad de la copia de este tipo de mandas en los epígrafes se debe al temor de que, como en el caso anterior, la iglesia no cumpla con lo dispuesto en el testamento. En previsión de ello, el autor decide darle publicidad al encargo.

Al avanzar la Baja Edad Media comienzan a aparecer en los testamentos otro tipo de mandas, véase la fundación de capellanías. Éstas consistían en la celebración de una misa diaria por el difunto a perpetuidad. Todo ello, se cargaba sobre unos determinados bienes - censos, tierras o cualquier otro tipo de heredad - lo que hacía que solamente las personas más acomodadas pudieran fundar una. Así lo reflejan testamentos como el de la reina María de Molina:

«E otrosí mando que compren en Valladolid o çerca de Valladolid heredades fasta en quantía de cuarenta mill maravedís para çinco capellanes perpetuos que canten por mi alma para siempre ...E otrosí, mando que compren en Toledo o en su término fasta en quantía de tres capellanías »37.

En Salamanca dos Epitaphia sepulcralia aluden a estas fundaciones. El primero es de Pedro de Paz, localizado en la iglesia de San Martín y fechado en 1367, dice así:

«...dio en esta yglesia la capellania de Padierno.... ${ }^{38}$.

El segundo Epitaphium es el de Pedro Vidal, en la iglesia del Sancti Spiritus, del año 1363:

«...el qual fundo la primera capellania en esta iglesia...»»3.

Comprobamos cómo, de nuevo, en estos epígrafes el rogatario toma como formulario las mandas del testamento.

La lectura de estas inscripciones nos sugiere, además, que la finalidad, al plasmar este tipo de disposiciones, estaría en una cierta pretensión de ensalzar al personaje que la dotó y en el intento de asegurar su consecución.

En otras ocasiones estos personajes relevantes encargaban en sus testamentos la construcción de un espacio concreto en la iglesia para albergar su cuerpo, la financiación de algún retablo, pintura etc. Son las mandas que podemos denominar artísticas, en las que se encargan este tipo de obras y se señala como

37 LARRIBA BACIERO, M: «El testamento de María de Molina» Signo. Revista de Historia de la Cultura Escrita, 2, Alcalá de Henares, 1995, pp. 201-211.

38 Apéndice, n. 7.

39 RODRÍGUEZ SUÁREZ, N: «La catedral de Salamanca y la publicidad. Algunos problemas» Hispania Sacra, vol. LVII, 116, 2005, p. 688-691. Apéndice, n. 6. 
se sufragarán esos gastos. El testamento del rey Pedro I, fechado en Sevilla el 18 de noviembre de 1362 nos sirve de ejemplo documental:

«é que sea enterrado en la capilla nueva que yo agora mando fazer...E mando para reparar la torre de Sancta María de Sevilla tres mil doblas doro Castellanas» ${ }^{40}$

Como siempre, podemos encontrar ejemplos en los epígrafes, lo que demuestra el origen de esas fórmulas. El Monumentum fundationis de una capilla en el convento de Santa Isabel, en Segovia, fechado en 1428, es el primero y dice:

«Esta capilla fundo, el ilustre, señor don Juan del Hierro, ... i doto una misa cada dia, su maiorazgo, por patron.... ${ }^{41}$.

También en Segovia encontramos la Roboratio de la capilla que hoy alberga el museo, en la iglesia de San Martín. En ella leemos:

«Esta capilla mando fazer el honrado cavallero Gonzalo de Herrera, ... dio para la fabrica mill maravedies de cense e dos gallinas ... ${ }^{42}$

En esta ocasión, la manda testamentaria copiada en el epígrafe, tendría la finalidad de publicitar la acción del testador. Que el espectador supiera que el espacio en el que se encuentra fue encargado por un personaje de cierta categoría, quien tenía la capacidad económica suficiente para perpetuar así su memoria.

Por último, también en los testamentos, en ocasiones, se hace referencia a donaciones y dotaciones a una entidad religiosa. De nuevo, podemos encontrar cierta similitud entre documento e inscripción. Tomamos como ejemplo del primero el testamento del canónigo de León y de Salamanca, Fernando Alfonso, fechado en 1294.

«Et mando a esta misma iglesia el mio heredamiento que yo he en Pelay Bravo: casas, vinnas, terras et bues et quanto yo y he, assi commo esta allanado ${ }^{43}$

Es fácil compararlo con ciertos Epitaphia, como el de Aldonza Martínez de Mayorga en la propia catedral de León, que dice así:

«...et mando al cabildo et a la obra desta eglesia todos los bienes que ella avia en Mayorga et en Valdemoro et en su termino; et mas diez mil maravedis para comprar otra heredat... ${ }^{44}$.

40 Testamento tomado de: ROSELL, C. (ed.): Crónicas de los reyes de Castilla desde don Alfonso el sabio hasta los católicos don Fernando y doña Isabel, Madrid, Atlas, 1953, pp. 593-598.

41 MARTÍNEZ ÁNGEL, L: Inscripciones ... pp. 124-125. Apéndice, n. 12.

42 MARTÍNEZ ÁNGEL, L: Inscripciones... pp. 209-210. Apéndice, n. 22.

43 MARTÍN MARTÍN, J.L. et al: Documentos de los archivos catedralicio y diocesano de Salamanca (siglo XII-XIII), Salamanca, Universidad de Salamanca, 1977, pp. 540-544.

44 Agradecemos al profesor Vicente García Lobo que nos facilitara esta inscripción que forma parte el estudio que lleva a cabo sobre el Corpus de epigráfico de León. Apéndice, n. 8. 
Otro ejemplo nos lo ofrece el Epitaphium sepulcrale de don Gómez Martínez, deán de Zamora, localizado en la catedral. Éste recoge con mayor detalle estas disposiciones.

«... Dexo por su alma al cabildo las sus casas qui son en la rua de Mercadillo, e en Andevias el palacio, otras casas de alquiler, unas vinas en Penedo, dos iugos de buis alinados, con un prado, un palonbar en Palacios, cuatro iugos de buis, los dos alinados, tres plados en san Frontes, veintiseis pares de casas fechas, tres cortezielas, todo lo que ava en Almeida, en Ordelos, en Calvilino... ${ }^{45}$

En esta misma línea, encontramos referencias a otro tipo de donaciones, no ya de heredades, sino de objetos litúrgicos u ofrendas a alguna imagen, siempre de acuerdo con las posibilidades del testador. El testamento de María de Luco, dona al convento de San Francisco de Daroca una palia.

«unos barveros de lino con listas cardenas para el pan vendito ${ }^{46}$

Catalina de Cardona, que en su codicilo dice:

«una capa de chamellot de grana y hun manto de chamellot de grana con su cortapisa alderredor de alto abaxo, de tapete negro, con tres trapos pora enpaliar al altar mayor los dias de las pascuas, con armas en medio de cardo con sus ferraduras cárdenas...» ${ }^{47}$

Resulta sencillo ponerlo en conexión con epígrafes como el Monumentum fundationis y dotationis del monasterio de Santa Ana, en Ávila.

«...diol muy grandes algos por do el es sostentado. Puso y muchas dueñas et de muy sancta vida, dioles su abadesa, entenduda et sabida, de libros et vestimentas la eglesia muy compida, et de muchas otras ioya la fizo enriquecida. Puso y capellanes que cada dia cantasen ${ }^{48}$

Parece que el autor encargaba que esta manda testamentaria pasase aquí a la piedra, buscando un ensalzamiento del personaje, pero más aún, pretendiendo que su acción sirviera de modelo al resto de los fieles, y más en los casos en los que el autor de la inscripción podía ser un miembro de la misma institución que recibía la donación.

En otras ocasiones, el epígrafe recoge varias mandas, permitiéndonos, así, conocer el contenido del testamento con mayor profundidad, testamento que en muchos casos ha desaparecido.

Así sucede con el Monumentum Aedificationis de la capilla de Pedro Solís, en la iglesia de San Nicolás, en Avilés, Asturias. En ellas leemos:

45 GUTIÉRREZ ÁlVAREZ, M: Corpus... p. 65. Apéndice, n. 4.

46 RODRIGO ESTEVAN, M. ${ }^{a}$ L: Testamentos... p. 158.

47 Idid., p. 159.

48 Apéndice, n. 5. 
«[Esta] capilla mando fazer a su costa el muy reverendo señor don Pedro de [Solis ...et dotola de muchos bienes espirituales] et otros temporales perpe[tuamente; e mando trasladar a ella los huesos de] los muy honrados [señores sus abuelos, padre y madre que estaban en]terrados en el monasterio [de San Francisco de esta villa de Aviles] ...celebrase cada dia misa [en la dicha capi$\| \mathrm{la}, \ldots{ }^{49}$.

Al leer este Epitaphium parece que estuviésemos delante de su testamento y que pudiéramos repasar las distintas mandas que en él se contenían, la manda artística, que encarga la construcción de la capilla, las dotaciones que se asociaron a ella, el traslado de sus antecesores, y el encargo o manda de misas.

Algo similar sucede con el Monumentum dotationis del altar en la Iglesia de San Nicolás en Ávila.

«...dotaron en este altar tres capellania[s] de tres misas de requiem, con su responso, ...tres anive[r]sarios cada anno. Dexaron dos yugadas de heredad en Escalonilla, con sus casas, i vnas casas a Sancta Cruz. Son patronos: el arçipreste de Avila i parientes mas çercanos, i cofrades de las animas de purgatorio. ...a esta iglesia, por el medio coro arriba, una yugada de heredad en el dicho lugar, con diez fanegas de trigo... una misa de requiem cantada, con proçesion ...Mas, dexaron a esta iglesia cien maravedis de çense ${ }^{50}$.

En él se indican mandas artísticas con la dotación de un altar, la fundación de una capellanía, tres misas de réquiem, y tres aniversarios, para los que se ofrecieron ciertas heredades. Se alude a las ofrendas funerarias y se concluye con una donación a la iglesia.

No hemos localizado este testamento, pero si podemos ponerlo en conexión con el de propio rey Pedro I citado más arriba:

«E otrosi mando la mi Capiella, é la que fue de los Reyes onde yo vengo, é cualquier otros ornamentos de Iglesia que yo tenga, que lo den todo á la Capilla que yo agora fago facer aquí en Sevilla do he de estar enterrado yo, e la dicha Reyna mi muger, é el dicho Infant mio fijo, que sea todo para la dicha Capilla, é quel dén dos pares de tablas que están y, unas que fueron de la Capilla de los Reyes, que son grandes, é otras que son más pequeñas, en que está el Lignum Domini: é mando que den tres alombras....E que den a sant salvador cerca de Navamorcuende docientas doblas doro...E otro si mando que pongan doce capellanes que canten continuamente Misas por mi alma, é por las almas de la dicha Reyna Doña Maria, mi muger, é el dicho Infant Don Alfonso...é que canten., é lo cumplan todo, así misas como aniversarios que han de decir los clérigos e las órdenes... ${ }^{51}$.

O con el testamento del canónigo Fernando Alfonso, que dice así:

49 DIEGO SANTOS, F: Inscripciones medievales de Asturias, Gijón, Principado de Asturias, 1993, p. 194. Apéndice, n. 20.

50 Apéndice, n. 23.

51 Testamento tomado de: ROSELL, C. (ed.): Crónicas... pp. 593-598. 
«Primeramente mando mi cuerpo a sepultura, si aquí morier, a la see Santa María de Salamanca, cabe mi padre et mi madre, et que tyren afuera el monumento en que yaç Perona Alfonso, mi hermana. Et mando a esta misma iglesia el mio heredamiento que yo he en Pelay Bravo....et que de por mio aniversario çincuenta morabetinos cadanno, et que de dineros pora un capellan perpetuo que cante misas de réquiem por $\mathrm{mi}$ alma et por el alma de mi padre... ${ }^{52}$

Estos ejemplos nos demuestran que efectivamente los testamentos sirvieron de formulario, en unos casos y de fuente en otros, para la creación de inscripciones. Y que la elección de un determinado tipo de mandas venía determinada por la funcionalidad que tuviera la inscripción, que en muchos casos, no era otra que la protección del cumplimiento de esas disposiciones ${ }^{53}$.

\section{Fórmulas pontificias}

Pero a pesar de que la copia de estas mandas testamentarias es la fórmula más frecuente en la Baja Edad Media, también han «prestado» sus fórmulas a nuestras inscripciones bajomedievales los documentos pontificios.

Es el caso de la concesión de indulgencias, estas inscripciones, toman como fuente el formulario de un documento completo, las litterae gratiosae. En el pilar que separa el ábside de capilla mayor del de la izquierda, en la catedral vieja de Salamanca, se conserva un Mandatum indulgentiae que refunde varias litterae gratiosae. La inscripción dice así:

«El papa Clemente quarto da ...cada dia cien dias que fazen veintidos quarentenas e media. El papa Nicholao quarto, de la orden de los frades menores, da... un anno e cuarenta dias, que fazen cada festa con su octavario, noventa e una quarentena e catorce dias...an perdones de quatro arcobispos e de veintinueve obispos que dan cada uno dellos quarenta dias de perdon ${ }^{54}$.

El archivo catedralicio de Salamanca custodia dos bulas de Nicolás IV relacionadas con esta inscripción. Ambas están datadas el 25 de febrero de 1289. La primera concede cuarenta días de indulgencia a quienes den limosna para las obras de la catedral. La segunda otorga un año y cuarenta días de indulgencia a los que visiten la iglesia de Santa María de Salamanca en la festividad o en su ochava. ${ }^{55}$

Vemos pues, que la relación entre el documento y la inscripción es evidente, pues el documento ha servido de formulario al epígrafe.

52 MARTÍN MARTÍN, J.L. et al: Documentos..., pp. 540-544.

53 MARTÍN LÓPEZ, M. ${ }^{a}$ E: «El documento... » y MARTÍN LÓPEZ, M. ${ }^{a}$ E: «Las inscripciones de la iglesia de San Salvador de Palat del Rey» Escritura y documentos. Los archivos como fuente de información, León, Junta de Castilla y León, 2007, p. 412.

54 Apéndice, n. 2.

55 MARTÍN MARTíN, J. L. et al: Documentos... Archivo Catedralicio de Salamanca (A.C.S.) caja 15, leg. 2, n. $^{\circ} 13$ y A.C.S. caja 16 , leg., n. ${ }^{\circ} 28$ fol. 8 v. 
Una fuente similar fue la que se utilizó para el Mandatum indulgentiae de la iglesia de San Martín, en la capilla de Santa Catalina, en Segovia. En este caso, el documento se ha perdido y únicamente se conserva el epígrafe.

«Los perdones que gana a quieraquier ag[a] limosna para el rreparo desta capilla o a quien uiniere a bisperas e a la uigilia o a qualquira ora del dia o dias fiestas de santa Calina la pascua de resorrecio de san Pedro, de santa Ysabel, son trescientos cinco anos y mas dias de perdon otrras quarentenas otorgados por el papa Paulo secundo» ${ }^{56}$

En todos los casos, lo que se pretende es dar publicidad, y poner en conocimiento de los fieles, este tipo de indulgencias a favor de las distintas iglesias. Una labor que esta institución supo asumir tempranamente del mundo romano ${ }^{57}$. Esta función se hace aún más patente si tenemos en cuenta que las Litterae gratiae eran expedidas en la lengua oficial del papado, el latín, y que la publicación del documento, a través de una inscripción en lengua vulgar, facilitaba la difusión de este mensaje entre una población a la que cada vez le quedaba más lejos la lengua que en otro tiempo había sido habitual.

\section{Las Datas}

También las datas de algunas inscripciones en lengua vulgar, nos recuerdan la correspondiente fórmula documental. Así el Epitaphium sepulcrale del chantre don Juan Alonso del Busto, en la catedral de Zamora se data mediante la fórmula de días por andar:

«... a tres dias por andar de iullio, anno del sennor de mill e quatro cientos e veynte e cinco annos... ${ }^{58}$

Esta fórmula es poco frecuente en las inscripciones, mientras que es fácil encontrarla en la documentación. De entre los muchos ejemplos documentales, hemos seleccionado uno perteneciente al monasterio de Santa María de la Vega. Se trata del documento de venta de Fernando Díez al monasterio de Vega, fechado el 21 de noviembre de 1245 redactado ya en lengua vulgar En él leemos:

«Facta carta $X$ días por andar $/{ }^{11}$ del mes de novembrio, kalendas decembris, era

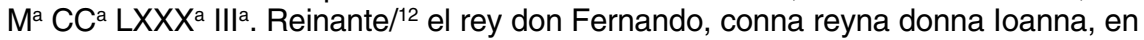
León, en Castila, en Toledo, $/{ }^{13}$ en Córdova. Merino maor, García Rodríguez. Obispo de León, don Monio/14 Álvarez. Tenente Maorga, Rui Fernández. En Ualdespino senores, ela prio/ ${ }^{15} \mathrm{ra}$, donna María Rodríguez, con todol convento de menester de Uega. Tenente ela casa, loán/ ${ }^{16}$ Fernández» 59

56 MARTÍNEZ ÁNGEL, L: Inscripciones ..., p. 145. Apéndice, n. 15.

57 GARCÍA LOBO, V: Los medios... p. 39.

58 GUTIÉRREZ ÁLVAREZ, M: Corpus... p. 78. Apéndice, n. 11.

59 DOMÍNGUEZ SÁNCHEZ, S: «Colección documental medieval de los monasterios de San Claudio de León, Monasterio de Vega y San Pedro de las Dueñas» Fuentes y estudios de historia leonesa, León, 90, Centro de Estudios e Investigación «San Isidoro», 2001, pp. 47-48. 
El ejemplo demuestra como efectivamente esta forma de datar la inscripción ha sido tomada de las fórmulas del documento.

Así mismo, este documento nos sirve para hablar de otra manera de fechar los acontecimientos: incluyendo, junto a la data crónica, un sincronismo. Es decir, se completa la fecha con un acontecimiento sucedido en el mismo tiempo. Así, en el documento anterior vemos como se han incluido las referencias a los personajes que ocupan los cargos más relevantes en ese lugar y en ese momento, aludiendo a los reyes, al merino mayor, al teniente de la villa, a los señores del Valdespino y al tenente de la casa.

En las inscripciones no es frecuente encontrar este tipo de datas, sin embargo, en la Roboratio del rey Enrique IV en el Alcazar de Segovia aparece así recogida la fecha:

«...seyendo alcayde Pedro de Muncharas criado del rrey ...» ${ }^{60}$

Se hace alusión al alcaide, un personaje relevante en ese momento, pues era, además, criado del rey. Pero en esta misma inscripción, y también en la data, se copia otra de las fórmulas empleadas en las datas de los documentos. Se trata de otro tipo de sincronismos, en los que se suele aludir a algún acontecimiento histórico de cierta importancia, que acompaña a la data cronológica. En el caso de la inscripción, se alude a la toma de la población de Ximena, en Andalucía. Esta es una fórmula que, en la documentación, venía ya empleándose desde la Alta Edad Media.

\section{Las Apprecationes}

También entre los epígrafes en lengua vulgar hemos localizado Apprecationes que son más propias de los documentos. En este caso, no son fórmulas eminentemente diplomáticas, pero sí son expresiones comunes, como la fórmula «que Dios mantenga», acompañando a un personaje real. Traemos aquí una carta de trueque entre doña Beatriz y su hijo Enrique III, de 1396. En ella al referirse a don Enrique se dice:

«por quanto entre vos mo fiio e mi señor el rey don Enrique que Dios mantenga e mi la dicha reyna...» ${ }^{61}$

Esa misma expresión se localiza en la Roboratio del Alcazar de Segovia, en la sala de las galeras, también al aludir al rey:

${ }^{60}$ MARTÍNEZ ÁNGEL, L: Inscripciones... pp.111-112. Apéndice, n. 14.

61 CASADO QUINTANILLA, B. (ed.): Láminas de la cátedra de Paleografía y Diplomática, Madrid, UNED, 2006, núm. 68. 
«...madre del muy alto e muy esclarecido senor rrei don luhan que Dios manttenga e dexe vevir e reinar/ por muchos tiempos e buenos... ${ }^{62}$

Comparando los dos textos observamos perfectamente que la inscripción ha tomado esta fórmula del documento.

\section{Las Sanctiones}

Para concluir este camino que nos ha llevado a través de diversas fórmulas diplomáticas, terminamos haciendo referencia a las Sanctiones. En la Alta Edad Media, es frecuente encontrar estas fórmulas en inscripciones. En la Baja Edad Media serán menos habituales, pero aún encontramos ejemplos, como el Mandatum de la iglesia parroquial de Piedrahita en Ávila.

«...dexando de dezir qualquiera cosa desto caen en pena de descomunion maior, e de quinientos maravedis para la fabrica de la dicha yglesia... ${ }^{63}$.

Dicha inscripción puede ser comparada con las muchas Sanctiones que aparecen en los documentos. He tomado el caso de una carta de donación de la abadesa de Santa María de Carbajal, Sancha García, que forma parte de la colección diplomática del monasterio de Santa María de Carbajal.

«He se per aventura contra este mío fecho vinier, sea maleyto e descomulgado, e con ludas en infierno sea dannado, e peche a vos $\mathrm{CC}^{\circ \mathrm{s}}$ morabedís.... ${ }^{64}$

El origen del formulario queda claramente reflejado también aquí.

En suma, y tras este periplo, esperamos haber mostrado, con el análisis de los muchos ejemplos expuestos, que el rogatario de las inscripciones diplomáticas solía utilizar los documentos como formularios para su trabajo.

\section{APÉNDICE}

\section{1.}

\section{c. 1172 .}

Epitaphium sepulcrale de Isabel.

A - SEGOVIA, Iglesia de San Esteban, muro oeste del pórtico. Letra gótica del siglo XIII. Original tardío. La parte derecha de la inscripción aparece muy deteriorada.

\footnotetext{
62 MARTÍNEZ ÁNGEL, L: Inscripciones... pp. 110-111. Apéndice, n. 10.

63 Apéndice, n. 18.

64 DOMÍNGUEZ SÁNCHEZ, S: «Colección ...», pp. 255-256.
} 
PUBL65: L. MARTÍNEZ ANGEL, Inscripciones medievales de la provincia de Segovia, León 2000, pp. 84-85.

(Cruz) Aqui iaze Isabel [...]ro de don Mu[n...]es conpannero[...]ribos deue u[... fa]zer cada anno [un aniversa]rio de missas [...]l[ s]ermana de [...] la era de mil [doscientos diez...].

$1289^{66}$.

Mandatum indulgentiae del papa Clemente IV, Nicolás IV, cuatro arzobispos y veintinueve obispos ${ }^{67}$.

B-SALAMANCA, Catedral vieja, muro entre el ábside central y el de la epístola. Letra gótica del S.XIV de $30 \mathrm{~mm}$. de altura. Copia documental. Bien conservada.

PUBL: J.M. ${ }^{a}$ QUADRADO, España sus monumentos y artes, su naturaleza e historia. Salamanca, Ávila y Segovia, Barcelona 1884, p. 50. AA.VV. Enciclopedia del románico en Castilla y León, 2002, p. 266 ${ }^{68}$.

REF: F. ARAUJO, La reina del Tormes. Guía histórico-descriptiva de la ciudad de Salamanca, Salamanca 1884, p. 203.

El papa Clemente quarto da a los que uinieren a las festas de sancta Maria con su ochauario, cada dia cien dias que fazen veintidos quarentenas e media. El papa Nicholao quarto, de la orden de los frades menores, da a todos los que uinieren a las festas de sancta Maria con su cruz ochauario, un anno e quarenta dias, que fazen cada festa con su ochauario, noventa e una quarentena e catorce dias. Item a los que uinieren a esta eglesia qualquier dia maior, mientre en las festas de sancta Maria, e ficieren aiudorio a la obra o a la luminaria an perdones de quatro arcobispos e de veintinueve obispos, que dan cada uno dellos quarenta dias de perdon.

65 Únicamente damos noticia de las obras que nos han servido de referencia.

66 La fecha la hemos tomado de las bulas reinterpretadas por la inscripción. Están fechadas en 1289.

67 El archivo catedralicio conserva dos bulas de Nicolás IV relacionadas con esta inscripción. Ambas están datadas el 25 de febrero de 1289. En la primera A.C.S. caj. 15, leg. 2, n. ${ }^{\circ} 13$, concede cuarenta días de indulgencia a quienes den limosna para las obras de la Catedral. La segunda A.C.S. caj. 16, leg. $1, n .{ }^{\circ} 28$, fol. $8 \mathrm{v}$, concede un año y cuarenta días de indulgencia a los que visiten la iglesia de Santa María de Salamanca la festividad o en su ochava.

68 Sólo aparece transcrita la parte final de la inscripción. 


\section{3.}

1321, diciembre, $28^{69}$.

Epitaphium sepulcrale de Adan Pérez, preste y canónigo de la catedral de León.

A- LEÓN, Catedral, claustro, lápida inserta en el muro. Letra gótica del S. XIV. Buen estado de conservación, salvo por una brecha que cruza el texto.

PUBL: J. M. a QUADRADO, Recuerdos y bellezas de España, León. Salamanca 1855, p. 93, (ed. fac. 1989).

Aqui iaz Adam Peres, preste et canonigo de Leon, que fino veintiocho dias de dezembrio era de mill et trescientos et cincuenta y nueve annos, et lexo a los bachilleres vnas casas en Leon, a la Pinganiella et viñas et heredamientos en Falvales, et por esto han de cantar cada anno en viesperas de Santa Cathalina las viesperas et otro dia la misa et fazer sa[lir] sobre sua sepultura.

1350, noviembre, 4, sábado.

Epitaphium sepulcrale de don Gómez Martínez, deán de Zamora.

A-ZAMORA, Catedral, muro de la epístola. Letra gótica del siglo XIV. Buena conservación.

PUBL: M. GUTIERREZ ÁLVAREZ, Corpus Inscriptionum Hispaniae Medievalium. Vol. I, Zamora. 1, Colección epigráfica, Turnhout-León, 1997, p.65.

Aqi ant esta altar ias don Gomez Martinus, dean de Camora. Dexo por su alma al cabildo las sus casas qui son en la rua de Mercadillo, e en Andevias el palacio, otras casas de alquiler, unas vinas en Penedo, dos iugos de buis alinados, con un prado, un palonbar en Palacios, cuatro iugos de buis, los dos alinados, tres plados en san Frontes, veintiseis pares de casas fechas, tres cortezielas, todo lo que ava en Almeida, en Ordelos, en Calvilino. E desto an a dar cada anno doscientos maravidis a un capellan que diga misa aqi en esta capiela seis dias cada seimana, dos en San Forontes (sic)e anle de fazer el cabildo por sienpre, cada mes mediado, un a[ni]bersario. E fino sabado, cuatro dias de novebrio, era de mill e trescientos ochenta e ocho anos. O tu ledor, di Pater Nostri por mi, que Dios de su regno a quien lo diga por ti.

69 Agradecemos a D. Vicente García Lobo, que nos haya facilitado la edición de esta inscripción, que forma parte de su Corpus de la catedral de León, aún inédito. 
5.

1350.

Monumentum aedificationis del monasterio de Santa Ana.

A- ÁVILA, Monasterio antiguo de Santa Ana, hoy sede de la delegación territorial de la Junta de Castilla y León, muro norte. Letra gótica del siglo XIV de $50 \mathrm{~mm}$. de altura. Buena conservación.

PUBL: G. GONZÁLEZ DÁVILA, Vidas y hechos del maestro don Alonso Tostado de Madrigal, obispo de Ávila, Salamanca 1611, p. 70.

Don Sancho, obispo de Auila, como sennor onrado, dio mui buen exemplo como faz el buen prelado, fizo este monasterio, Sant Benito llamado, et diol muy grandes algos por do el es sostentado. Puso y muchas dueñas et de muy sancta vida, dioles su abadesa, entenduda et sabida, de libros et vestimentas la eglesia muy compida, et de muchas otras ioya la fizo enriquecida. Puso y capellanes que cada dia cantasen, et las oras del dia todas muy bien rezasen, et por todos los finados cada dia rogasen, ca dioles buenas rentas con que lo bien pasasen, e por que este monesterio fuese meior guardado, e de todos sus algos fuese bien mamparado, dio la uisitacion a qualquier que fues prelado, obispo que fues de Avila, e non de otro reglado. Andaua estonce el era, quando el fue acabado, en mill et trescientos annos, segunt diz el dictado, et mas ochenta y ocho, por meior se remembrado, et dio gracias a Dios el obispo mucho onrado.

6.

1363, septiembre, 27.

Epitaphium sepulcrale de Pedro Vidal presbítero beneficiado de San Martín.

C-SALAMANCA, Iglesia de Sancti Spiritus, nave de la izquierda, cista del sepulcro. Letra humanística de $41 \mathrm{~mm}$. de altura. Renovatio. Bien conservada.

PUBL: J. M. ${ }^{a}$ QUADRADO, España, sus monumentos y arte, su naturaleza e historia. Salamanca, Ávila y Segovia, Barcelona 1884, p. 97. F. ARAUJO, La reina del Tormes. Guía histórico-descriptiva de la ciudad de Salamanca, Salamanca 1884, p. 237. E. CARRERO SANTAMARÍA, La catedral de Salamanca y la publicidad. Algunos problemas, Murcia 2005, pp. 690 y 698.

Aqui yace el lizenciado Pedro Vidal, presvitero beneficiado que fue de Sanct Martin, el qual fundo la primera capellania en esta iglesia. Son patronos y administradores perpetuos della y de mas agregadas los hombres buenos desta parochia. Fallescio a 27 de setienbre anio de 1363. 


\section{7.}

1367.

Epitaphium sepulcrale del doctor Pedro de Paz.

B-SALAMANCA, Iglesia de San Martín arcosolio a los pies. Letra humanística del siglo XVIII de $47 \mathrm{~mm}$. Renovatio. Buen estado de conservación.

PUBL: F. ARAUJO, La reina del Tórmes. Guía histórico-descriptiva de la ciudad de Salamanca, Salamanca 1884, p.222.

Aqvi jaze el doctor Pedro de Paz que dio en esta yglesia la capellania de Padierno de qui son patronos i a cura y parochianos. Fino en la era de 1405. Amen.

\section{8.}

1383, junio, 4, jueves ${ }^{70}$.

Epitaphium sepulcrale de Aldonza Martínez de Mayorga, viuda de Diego García.

A- LEÓN, Catedral, claustro, lápida incrustada en el muro. Letra gótica del siglo XIV. Buena conservación.

PUBL: J. M. ${ }^{a}$ QUADRADO, Recuerdos y bellezas de España. León, Salamanca 1989 , p. 93.

Aqui iaze Aldonza Martinez de Mayorga que Dios perdone, mugier que fue de Diego Garcia, que fino iueves, quatro dias del mes de iunio, anno Domini millesimo tricentesimo octogesimo tertio. Et mando al cabildo et a la obra desta eglesia todos los bienes que ella auia en Mayorga et en Valdemora et en su termino; et mas diez mil maravedis para comprar otra heredat. Dezit Pater noster por su anima. Amen.

9.

S.XIV.

Donatio de ciertos bienes a la iglesia por parte de Mendo y su mujer Oro Gil.

A-SEGOVIA, Iglesia de San Justo de Segovia, muro de la izquierda, entrada al ábside. Letra gótica del siglo XIV de $30 \mathrm{~mm}$. de altura. La inscripción presenta algunos desperfectos.

70 Agradecemos a Don Vicente García Lobo que nos haya facilitado esta inscripción. 
PUBL: L. MARTÍNEZ ANGEL, Inscripciones medievales de la provincia de Segovia, León 2000, pp. 104-106.

Aondra de Dios et de Sancta Maria et de todos los sanctos don Mendo(sic) Pero et su mvgier donna Oro Gil dieron seis arençadas de c[...]maras et quatro que son en la Lastriella sobre Cigondela por capellania a los prestes de sancti luste que son et seran, et nos los prestes don Macarbo et Diego Peres et don Martin et don Pedro lones obligamos a nos et a los otros p[reste]s que vernan despues de nos que cantemos cada dia una missa de requiem al altar de Sant Marcos por sus almas et salgamos a su bvessa; si non los dias que non deuen dezir de requiem et que non cantaren missas et si esto non complieren por cada dia pechen para pan el dia de la[di] la meatat a don Martino Pero et c[...]et la meatat a[sanct] luste qui $[\ldots]$

10.

1412.

Roboratio en el Alcazar de Segovia.

A- SEGOVIA, Alcazar, sala de la galera. Letra gótica minúscula del siglo $X V$. Buena conservación.

PUBL: L. GUTIERREZ ÁNGEL, Inscripciones medievales de la provincia de Segovia. Colección epigráfica, León 2000, pp.110-112.

Esta obra mando faser la muy esclarecida senora reina dona Catalina tutora rregidora madre del muy alto e muy esclarecido senor rrei don luhan que Dios manttenga e dexe vevir e reinar por muchos tiempos e buenos amen e fisola facer por mandado de la dicha senora reina Diego Fernandez vecero de Arevalo vasallo de dicho senor rrei acabose esta dicha obra en el anno del nascimiento de nuestro Senor lehu Christo de mil quatrocientos e doce annos. En el nonbre del padre e del fillio e del Spiritu santo amen. Senor lehu Christo yo protesto de ante de la vuestra santisima magestad que en este dia e por sienpre iamas io quiero vevir e morir en la vuestra santa fe catolica amen.

11.

1425, julio, 29, domingo.

Epitaphium sepulcrale del chantre don Juan Alonso del Busto.

A- ZAMORA, Catedral, muro de separación entre nave central. Letra gótica del siglo XIV $38 \mathrm{~mm}$. de altura. Buena conservación. 
PUBL: M. GUTIERREZ ÁLVAREZ, Corpus Inscriptionum Hispaniae Medievalium. Vol. I, Zamora. 1, Colección epigráfica, Turnhout-León, 1997, p. 78.

Aqui en el suelo delante deste altar iaze don luan Alonso del Busto, chantre desta iglesia, que Dios perdone. E fino domingo, a tres dias por andar de iullio, anno del sennor de mill e quatro cientos e veynte e cinco annos. O tu leedor di Pater Nostri por mi. Que Dios perdone a ti e a mi.

12.

1428.

Monumentum fundationis de una capilla.

B- SEGOVIA, Convento de Santa Isabel, friso pintado. Letra humanística. Renovatio. Buena conservación.

PUBL: L. MARTÍNEZ ÁNGEL, Las inscripciones medievales de la provincia de Segovia. Colección epigráfica, León 2000, p. 124-125.

Esta capilla fundo, el ilustre, señor don Juan del Hierro, canonigo i dean de esta ciudad i doto una misa cada dia, su maiorazgo, por patron. Fallecio año mil cuatrocientos veintiocho.

13.

1452.

Epitaphium sepulcrale de cierta María.

A- ZAMORA, Iglesia de Santa María de Horta, muro derecho de la nave. Letra gótica minúscula de 40mm. de altura. Aparece algo deteriorada.

PUBL: M. GUTIERREZ ÁLVAREZ, Corpus Inscriptionum Hispaniae Medievalium. Vol. I, Zamora. 1, Colección epigráfica, Turnhout-León, 1997, pp. 80-81.

Aqui ias Ma[ria p...], que Dios aya, que dexo a esta iglesia quatro pares de casas porque diga una misa cantada cada biernes con su responso sobre esta sepoltura. Fallescio anno de mil cuatrocientos cincuenta y [dos]. 
14.

1456.

Roboratio del rey Enrique IV de una estancia del Alcazar.

B-SEGOVIA, Alcazar, salón del trono, cenefa en lo alto del muro. Letra gótica minúscula del siglo XV. Renovatio. Buena conservación.

PUBL: L. MARTÍNEZ ÁNGEL, Inscripciones medievales de la provincia de Segovia. Colección epigráfica, León 2000, pp. 134-136.

Esta quadra mando faser el muy alto e muy poderoso ylustre senor el rey don Enrique el quarto, la qual se acabo de obrar en el anno del nascimiento de Nuestro Senor lesucristo de mill e quatrocientos e cinquenta e seis annos, estando el senor rrey en la gerra de los moros, quando gano a Ximena, la qual obra fiso por su mandado Francisco de Auila, mayordomo de la obra, seyendo alcayde Pedro de Muncharas criado del rrey, la qual obra ordeno e obro maestro Xadel alcalde.

15.

Entre 1464 y 1471.

Mandatum indulgentiae para la limosna a las iglesias.

A-SEGOVIA, Iglesia de San Martín, capilla de Santa Catalina. Letra gótica minúscula del siglo $X V$. Buena conservación.

PUBL: L. MARÍNEZ ANGEL, Inscripciones medievales de la provincia de Segovia, León 2000, p. 145.

Los perdones que gana a quieraquier ag[a] limosna para el rreparo desta capilla o a quien uiniere a bisperas e a la uigilia o a qualquira ora del dia o dias fiestas de santa Calina, la pascua de resorrecio, de san Pedro, de santa Ysabel, son trescientos cinco anos y mas dias de perdon otrras quarentenas otorgados por el papa Paulo secundo.

16.

1472, abril, 14.

Epitaphium sepulcrale de Lope Ramírez y su segunda esposa, Isabel González de Coca.

A-ÁVILA, ARÉVALO, Iglesia de San Pedro. Desaparecida.

B-Copia literaria de Real Academia de la Historia. Colección Salazar y Castro, sign. D-56 (9/329bis), ms. 30.538, f. 22. 
En este arco están enterrados los nobles señores el regidor Lope Ramirez, hiio de Francisco Ramirez, y nieto de Alfonso Ramirez, criados del rey don loan el segundo, que estan enterrados en Nuestra Sennora de la Merced de Olmedo; murio a catorze dias del mes de abril, anno MCCCCLXXII; y su segunda muger, Isabel Gonçalez de Coca, hiia de Fernan Pamo, de cuyo matrimonio ovieron tres solos y unicos hiios: Bernardino Ramirez, Francisco Ramirez, regidor, y Diego Ramirez; y entre otras buenas obras que dexo, doze aniversarios en cada mes, uno que dizen los sennores del cabildo en esta capilla.

17.

C. 1474 .

Epitaphium sepulcrale de Sebastián Ruano Mozo.

A- ZAMORA, Iglesia de San Juan. Desaparecida.

B-Copia literaria de Memorias de Zamora, II, p. 49.

PUBL: M. GUTIERREZ ÁLVAREZ, Corpus inscriptionum Hispaniae medievalium. Vol. I, Zamora. 1, Colección epigráfica, Turnhout-León, 1997, p. 85.

Aqui esta sepultado Sebastian Ruano Mozo. Dejo a la cofradia de Nuestra Señora una misa, a la fabrica doce cargas de pan en cada anno, con cargo que se han de decir una misa rezada todos los dias de la semana y dos responsos y un aniversario el dia de San Esteban, para siempre jamas. Finado en el anno mil quatrocientos[...].

18.

1480.

Mandatum a los beneficiados y capellanes de la iglesia.

A-ÁVILA, PIEDRAHÍTA, Iglesia parroquial, brazo norte del crucero. Letra gótica minúscula del siglo XV. Inédita.

(Cruz) Son obligados los beneficiados he capellanes desta yglesia de dezir cada Ivnes una misa rezada, he cada viernes otra cantada, con sus responsos, he el dia de señor sant Andres, una misa cantada e su vegilia. He dexando de dezir qualquiera cosa desto caen en pena de descomvnion maior, e de quinientos maravedis para la fabrica de la dicha yglesia. He los clerigos que non estovieren a los dichos oficios non ganan[...]de ochenta. 
19.

$1483^{71}$.

Epitaphium sepulcrale del caballero Lope de Cernadilla,

A-SEGOVIA, Museo provincial. Letra gótica minúscula de $40 \mathrm{~mm}$. de altura. Buena conservación.

PUBL: L. MARTÍNEZ ÁNGEL, Inscripciones medievales de la provincia de Segovia, León 2000, pp. 127-128.

Aqui esta el honrrado cavallero Lope de Cernadilla, fiio de Nuno Peres de Cernadilla e de dona Urraca San de Virves, nieto de Fernan Sans de Virves e de dona Mayor de Pidrola; fue capitan del señor rey don Erriq[ue] e corregidor de Asturias e de otras muchas cibdades, el qual dexo a esta iglesia quinse fanegas de pan de encense. Fino anno de mil cuatrocientos ochenta y tres anos.

\section{0.}

1499.

Monumentum aedificationis de la capilla de Pedro Solís.

A- ASTURIAS, AVILÉS, Iglesia de San Nicolás, puerta ojival. Casi desaparecida.

B-Copia literaria de F. DIEGO SANTOS, Inscripciones medievales de Asturias, Gijón 1994, p. 194.

PUBL: F. DIEGO SANTOS, Inscripciones medievales de Asturias, Gijón 1994, p. 194.

[Esta] capilla mando fazer a su costa el muy reverendo señor don Pedro de [Solis protonotario et cubiculario del nuestro] muy Santo Padre Alexandre sesto [arcediano de Babia, abad de Santa Maria], maestre escuela de Leon e canonigo [de Toledo; et dotola de muchos bienes espirituales] et otros temporales perpe[tuamente; e mando trasladar a ella los huesos de]los muy honrados [señores sus abuelos, padre y madre que estaban en]terrados en el monasterio [de San Francisco de esta villa de Aviles por] cuyas animas fue la vo[luntad de dicho señor don Pedro de Solis se] celebrase cada dia misa [en la dicha capilla, la cual por su voluntad fizo] facer a mi Alonso Rodriguez de Leon [prior en la iglesia de Oviedo, su primo, en el año] del nacimiento de [Nuestro Señor Jesucristo de mil cuatrocientos noventa y nueve años] e fue maestro de ella [Fernan Rodriguez de Berceros, vecino de Oviedo].

71 En L. MARTÍNEZ ÁNGEL, Inscripciones..., pp.127-128 data la inscripción en 1433, el error se debe a una mala lectura de la $L$ de cincuenta que interpreta como una $E$. 
21.

S. $X V^{72}$.

Mandatum al cura y clérigos de la iglesia de San Vicente.

A- ÁVILA, Iglesia de San Vicente, brazo norte del crucero. Letra gótica minúscula de $80 \mathrm{~mm}$. de altura. Buena conservación.

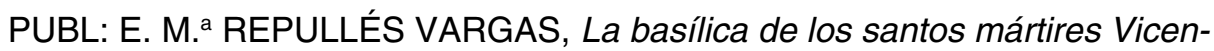
te, Sabina y Cristeta, en Ávila, Madrid 1894, p. 116.

Cura y clerigos desta iglesia an de dezir cada semana perpetuamente en esta capilla, en el altar de san Antonio, lunes, misa de Requiem, miércoles, de la Cruz, sabado, de Nuestra Señora, con responsos, y dia de la Trinidad, bisperas y vigilia, y el siguiente, misa cantada, y dia de san Antonio, otro tanto, dia de san Vicente de otubre, lo mismo, por las almas de Gomez Macav y su muger y difuntos. Dotaron para esto tres yugadas deredad en Rio Cavado. Y si algo desto faltaren, que la eredad buelua al patron, y de veinticinco maravedis a Nuestra Señora de Sansoles y de las Vacas. Izieron este retablo questa frontero.

22.

S. XV.

Roboratio de la capilla.

A- SEGOVIA, Iglesia de San Martín, museo parroquial, alrededor de toda la capilla. Letra gótica minúscula del siglo XV de 170-180 mm. de altura. Buena conservación.

PUBL: L. MARTÍNEZ ÁNGEL, Inscripciones medievales de la provincia de Segovia, León 2000, pp. 209-210.

Esta capilla mando fazer el honrado cavallero Gonzalo de Herrera, criado del mui alto e mui poderoso principe el rei Don Fernando, Nuestro Sennor, el qual le llamo cavallero despuelas doradas en el conbate de la ciudad de Ronda e dio para la fabrica mill maravedies de cense e dos gallinas e dexo dos misas cada semana.

72 Agradecemos al profesor Santiago Domínguez Sánchez el facilitarnos la edición de esta inscripción, así como del resto de las alusivas a Ávila. Todas ellas, forman parte de su Corpus de la provincia de Ávila, aún por publicar. 
23.

S. XV.

Monumentum dotationis del altar de la iglesia.

A-ÁVILA, Iglesia de San Nicolás, altar mayor. Letra gótica minúscula del siglo XV. Bien conservada. Inédita.

Iuan de Pinilla e Isabel Ferrandez, su muger, dotaron en este altar tres capeIlania[s] de tres misas de requiem, con su responso, por si, e sus defuntos: martes, iueves i sabado, en saliendo el sol; i tres anive[r]sarios cada anno. Dexaron dos yugadas de heredad en Escalonilla, con sus casas, i vnas casas a Sancta Cruz. Son patrones: el arçipreste de Avila i parientes mas çercanos, i cofrades de las animas de purgatorio. E mas, dieron a esta iglesia, por el medio coro arriba, una yugada de heredad en el dicho lugar, con diez fanegas de trigo de çense cada anno, para el cura i beneficiado desta iglesia, con que diga cada lunes, en saliendo el sol, una misa de requiem cantada, con proçesion alrededor de la iglesia, por las animas de purgatorio, i por ellos i sus defuntos. Ai escrituras tras esta piedra. Mas, dexaron a esta iglesia cien maravedis de çense. 